\title{
Nonsteroidal Anti-Inflammatory Drugs Alter the Human Mesothelial Pleural Permeability via Ion Cellular Transportation by Inhibiting Prostaglandin Synthesis
}

\author{
Vasileios K. Kouritas ${ }^{\mathrm{a}, \mathrm{b}}$ Charalambos Zisis $^{\mathrm{a}}$ Ion Bellenis ${ }^{\mathrm{a}}$ \\ Konstantinos I. Gourgoulianis ${ }^{c}$ Paschalis A. Molyvdas ${ }^{b}$ Chrisi Hatzoglou ${ }^{b}$ \\ a Department of Thoracic and Vascular Surgery, Evangelismos Hospital, Athens, and bepartment of Physiology, \\ Medical School, University of Thessaly, and ' Department of Thoracic Diseases, Larissa University Hospital, \\ Larissa, Greece
}

\section{Key Words}

Human · Ion transportation $\cdot$ Mesothelial $\cdot$ Nonsteroidal anti-inflammatory drugs $\cdot$ Permeability $\cdot$ Pleura $\cdot$

Prostaglandin

\begin{abstract}
Background: Nonsteroidal anti-inflammatory drugs (NSAIDs) are used in clinical practice as analgesics or anti-inflammatory drugs. Studies have implicated them in participating in permeability throughout various tissues such as the kidneys and lungs. Objective: The effect of NSAIDs on the pleural permeability and the underlying mechanisms whereby this effect is mediated were investigated. Methods: Parietal pleural specimens were obtained from patients subjected to thoracic surgery and were mounted in Ussing chambers. Solutions containing paracetamol, acetylsalicylic acid, diclofenac, lornoxicam, parecoxib and ibuprofen were added in the chambers facing the pleural and the outer-pleural surface. Prostaglandin $E_{2}$ was similarly used to investigate prostaglandin synthesis involvement at low and high doses. Amiloride- and ouabain-pretreated specimens were used in order to investigate ion transportation involvement. Trans-
\end{abstract}

mesothelial resistance $\left(\mathrm{R}_{T M}\right)$ was determined as a permeability indicator. Results: Paracetamol, acetylsalicylic acid, diclofenac, lornoxicam and ibuprofen increased $\mathrm{R}_{T M}$ on the pleural and outer-pleural surface, inhibited by amiloride and ouabain. Parecoxib had no effect on the $\mathrm{R}_{T M}$. Prostaglandin decreased $\mathrm{R}_{T M}$ on the pleural and outer-pleural surface inhibited by amiloride, ouabain and ibuprofen. Conclusion: NSAIDs, except parecoxib, induce a rapid decrease of the pleural permeability by inhibiting cellular transportation, an effect that is mediated by prostaglandin synthesis inhibition.

Copyright $\odot 2012$ S. Karger AG, Basel

\section{Introduction}

The nonsteroidal anti-inflammatory drugs (NSAIDs), apart from anti-inflammatory and analgesic properties, have been implicated in causing permeability alterations in various tissues such as the kidneys and lungs, interfering with ion transportation across epithelial tissues $[1,2]$. In most cases these alterations are being mediated via interference with prostaglandin production [1-3].

\section{KARGER}

Fax +4161306 1234

E-Mail karger@karger.ch

www.karger.com (c) 2012 S. Karger AG, Basel

0025-7931/12/0841-0062\$38.00/0

Accessible online at:

www.karger.com/res
Vasileios K. Kouritas, MD, $\mathrm{PhD}$

15-17 Keas St., Chalandri

GR-15234 Athens (Greece)

Tel. +306974405281

E-Mail kouritas@otenet.gr 
In pleura, the anti-inflammatory drugs, and more specifically NSAIDs, are thought to play an important role in exudate progression [4] while they are shown to interfere with the pleurodesis quality $[5,6]$. Furthermore, histamine, an inflammatory hormone, was shown to cause permeability alterations in human parietal pleura mainly by interacting with the $\mathrm{H}_{1}$ histaminic receptors and eventually interfering with the normal process of transmesothelial ion transportation [7].

The aim of the present study is to investigate the effect of NSAIDs on the electrophysiology of the human parietal pleura. Additionally, we investigate the mechanisms whereby these drugs mediate their effect such as the inhibition of prostaglandin synthesis and the involvement of ion cellular transporters.

\section{Materials and Methods}

\section{Study Subjects}

Intact sheets of human parietal pleura were obtained from 12 patients who underwent thoracic surgery for lung cancer (via thoracotomy or thoracoscopy). The pleural specimen was obtained from an area distant to the lung tumor. A piece from each dissected specimen was sent for histopathological examination. All specimens included in the study were proven to be free of any disease as per histopathological reports. Patients with pleural effusion preoperatively were excluded from the study. After its dissection, each remaining specimen was placed in Krebs solution, preoxygenated at $95 \% \mathrm{O}_{2}-5 \% \mathrm{CO}_{2}$ and cooled at $4{ }^{\circ} \mathrm{C}$, and transferred to the laboratory within $30 \mathrm{~min}$.

The study was approved by the Local Ethics Committee and informed signed consent was obtained from all patients participating in the study.

\section{Study Design}

Experiments were conducted with different NSAID solutions added towards the pleural and outer-pleural surfaces of stripped pleural specimens. Amiloride- and ouabain-pretreated specimens were used to investigate ion transportation involvement in the NSAID effect on pleura. Experiments with prostaglandin $E_{2}$ were also performed with amiloride, ouabain and ibuprofen in order to investigate prostaglandin synthesis involvement in this effect.

\section{Methods}

The Krebs solution used throughout the whole study was balanced at $\mathrm{pH} 7.45$ and contained $117.5 \mathrm{~mm} \mathrm{NaCl}, 1.15 \mathrm{~mm}$ $\mathrm{NaH}_{2} \mathrm{PO}_{4}, 24.99 \mathrm{~mm} \mathrm{NaHCO} 3,5.65 \mathrm{~mm} \mathrm{KCl}, 1.18 \mathrm{~mm} \mathrm{MgSO}$, $2.52 \mathrm{mM} \mathrm{CaCl}_{2}$ and $5.55 \mathrm{~mm}$ glucose.

The pleural surface (which faces the pleural cavity in vivo) will be referred to as the mesothelial surface, whereas the outer-pleural surface (which faces the chest wall) will be referred to as the interstitial surface.

The pleural specimens were mounted as planar sheets of tissue in Ussing-type chambers (model DVC-1000; World Precision
Instruments, Sarasota, Fla., USA), were bathed in Krebs solution on both sides and perfused continuously with $95 \% \mathrm{O}_{2}-5 \% \mathrm{CO}_{2}$ gas mixture heated to $37^{\circ} \mathrm{C}$ in order to ensure tissue viability [8-10].

Following mounting, the pleural specimens were equilibrated for $30 \mathrm{~min}$. Transmesothelial potential difference (PD) was then measured for $30 \mathrm{~min}$, with or without the application of a current of variable intensity $(0 \pm 400 \mu \mathrm{A})[8-10]$, constituting the control potential difference. Fifty control experiments were performed.

Following the equilibration period and control measurements, solutions containing different NSAIDs (paracetamol $1 \mathrm{~g}$, acetylsalicylic acid $325 \mathrm{mg}$, ibuprofen $300 \mathrm{mg}$, lornoxicam $8 \mathrm{mg}$, diclofenac $75 \mathrm{mg}$ or parecoxib $100 \mathrm{mg}$ ) were added sequentially on both surfaces in order to investigate their effects on pleural tissue ( $\mathrm{n}=7$ experiments for each drug, $\mathrm{n}=7$ experiments for each side). In other experiments, in order to investigate whether prostaglandins interfere in permeability alterations caused by NSAIDs, prostaglandin $\mathrm{E}_{2}$ (Sigma Chemical Co., St. Louis, Mo., USA) was used in the same manner at one low concentration $\left(10^{-6} \mathrm{M}\right)$ and one high concentration $\left(10^{-4} \mathrm{M}\right)(\mathrm{n}=7$ experiments for each concentration, $\mathrm{n}=7$ experiments for each side). In another group of experiments, specimens were pretreated with the $\mathrm{Na}^{+}$channel blocker amiloride $(10 \mu \mathrm{M}$; Sigma Chemical Co.) $[9,10]$ and the $\mathrm{Na}^{+} / \mathrm{K}^{+}$pump inhibitor ouabain (10 $\mu \mathrm{M}$; Sigma Chemical Co.) [9, 10] for at least $30 \mathrm{~min}$ before the addition of each NSAID solution, in order to clarify whether ion cellular transporters take part in their effect on human pleura ( $n=7$ experiments for each drug, $n$ $=7$ for each surface). Experiments with tissues pretreated with amiloride and ouabain before the addition of prostaglandins at high doses (based on observations made before) were also used in order to clarify the involvement of cellular transporters in prostaglandin effect ( $\mathrm{n}=7$ experiments for each drug, $\mathrm{n}=7$ for each surface). Finally, given that ibuprofen is widely used as a prostaglandin inhibitor [11], experiments with the coaddition of ibuprofen and prostaglandin were also conducted $(\mathrm{n}=7$ experiments for each drug, $\mathrm{n}=7$ for each surface). In total, 126 experiments were conducted.

In order to ensure that the recorded results were due to drug action and not due to mechanical perturbation while emptying and refilling the chambers, the experiments were conducted using solely Krebs solution (data not shown as no electrical changes in PD were observed). The PD following electrical stimulation with the application of a current $(0 \pm 400 \mu \mathrm{A})$ was measured 1 , $5,10,30$ and 60 min following the addition of each solution. All solutions were freshly prepared before every experiment, heated to $37^{\circ} \mathrm{C}$ and continuously perfused with $95 \% \mathrm{O}_{2}-5 \% \mathrm{CO}_{2}$ gas mixture.

$\mathrm{R}_{T M}$ was calculated from the PD according to Ohm's law [8-10].

\section{Analysis}

Statistical analysis was performed using the statistical package SPSS ver. 10.00 for Windows (Statistical Package for the Social Sciences; SPSS Inc., Chicago, Ill., USA). Data are expressed as mean $\mathrm{R}_{T M}\left(\Omega \cdot \mathrm{cm}^{2}\right) \pm$ standard error of mean (SE) within the first minute. Statistical significance was determined by paired $t$ test. Comparison among groups was performed by one-way ANOVA (Bonferroni's post hoc test). $\mathrm{p}$ values $<0.05$ were considered significant. 


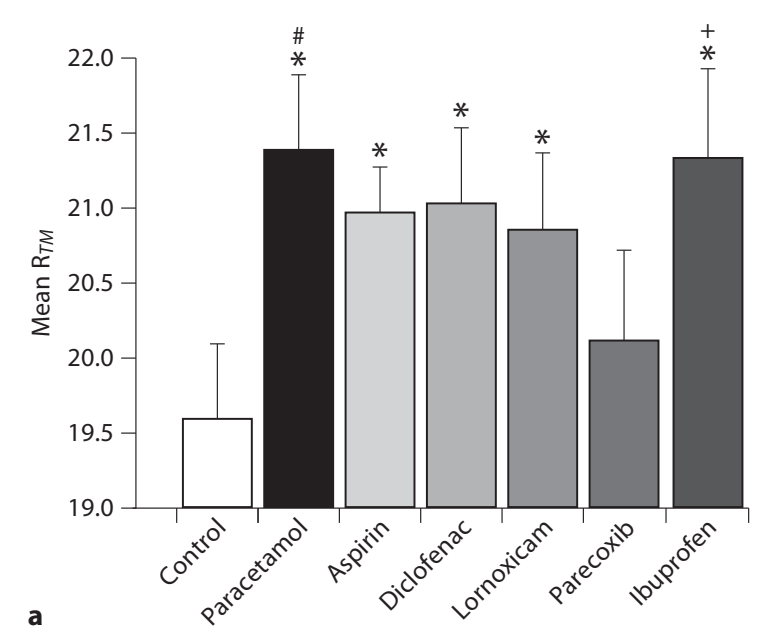

a

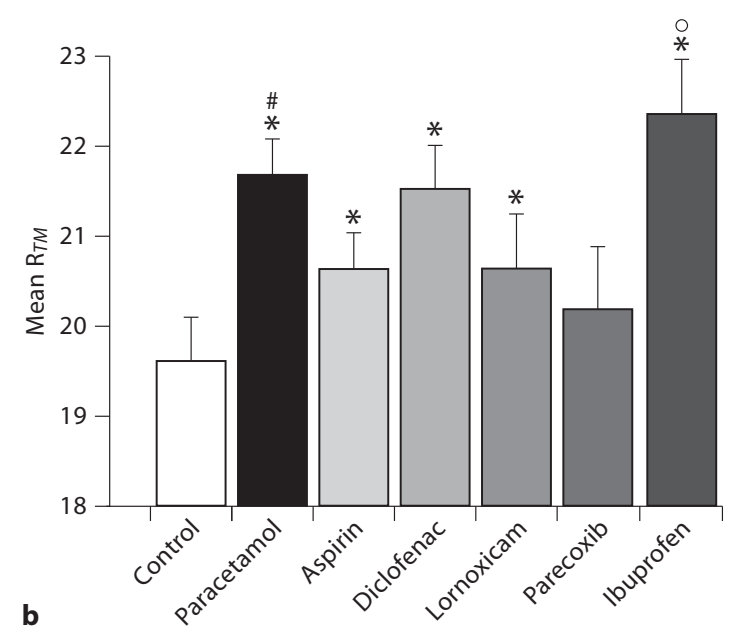

Fig. 1. Effect of paracetamol, acetylsalicylic acid, diclofenac, lornoxicam, parecoxib and ibuprofen on the $\mathrm{R}_{T M}$ of the mesothelial (a) and interstitial (b) surfaces of the human parietal pleura, within the first minute after addition. Values are expressed as mean $\mathrm{R}_{T M} \pm \mathrm{SE}$ in $\Omega \cdot \mathrm{cm}^{2}$. ${ }^{*} \mathrm{p}<0.05$ vs. control, ${ }^{+} \mathrm{p}<0.05$ for ibuprofen mesothelial vs. parecoxib, ${ }^{*} \mathrm{p}<0.05$ for paracetamol vs. parecoxib and ${ }^{\circ} \mathrm{p}<0.05$ for ibuprofen interstitial vs. all NSAIDs.

\section{Results}

\section{Effect of Anti-Inflammatory Agents on the}

Electrophysiology of the Human Parietal Pleura

The addition of paracetamol significantly increased $\mathrm{R}_{T M}$ on both the mesothelial ( $\mathrm{p}=0.032$, fig. 1a) and the interstitial surfaces $(p=0.03$, fig. $1 b)$ of the pleura within the first minute after addition. Amiloride inhibited this

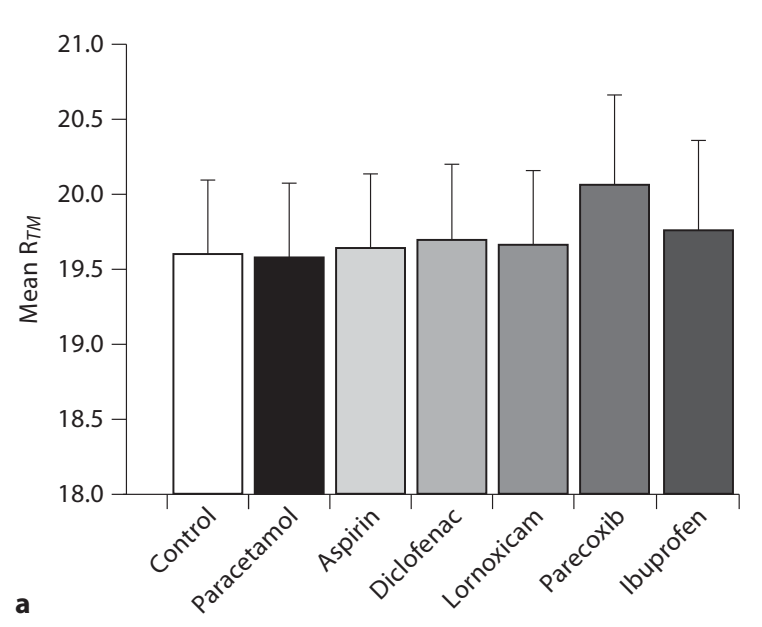

a

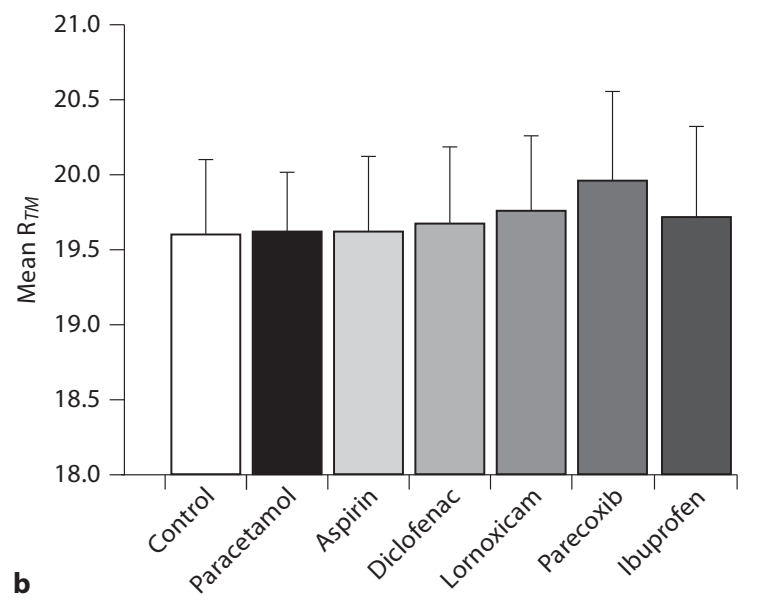

Fig. 2. Effect of amiloride on the effect induced by paracetamol, acetylsalicylic acid, diclofenac, lornoxicam, parecoxib and ibuprofen on the $\mathrm{R}_{T M}$ of the mesothelial (a) and interstitial (b) surfaces of the human parietal pleura, within the first minute after addition. Values are expressed as mean $\mathrm{R}_{T M} \pm \mathrm{SE}$ in $\Omega \cdot \mathrm{cm}^{2}$.

effect on both the mesothelial ( $p=0.932$, fig. $2 a$ ) and interstitial surfaces ( $\mathrm{p}=0.993$, fig. $2 \mathrm{~b}$ ). Ouabain also inhibited paracetamol's effect on the mesothelial $(\mathrm{p}=0.892$, fig. $3 a$ ) and interstitial surfaces ( $p=0.923$, fig. $3 b$ ).

The addition of acetylsalicylic acid acutely and significantly increased $\mathrm{R}_{T M}$ on both the mesothelial ( $\mathrm{p}=0.012$, fig. 1a) and interstitial surfaces $(p=0.058$, fig. $1 b)$ of the pleura. Amiloride inhibited this effect on both the meso- 


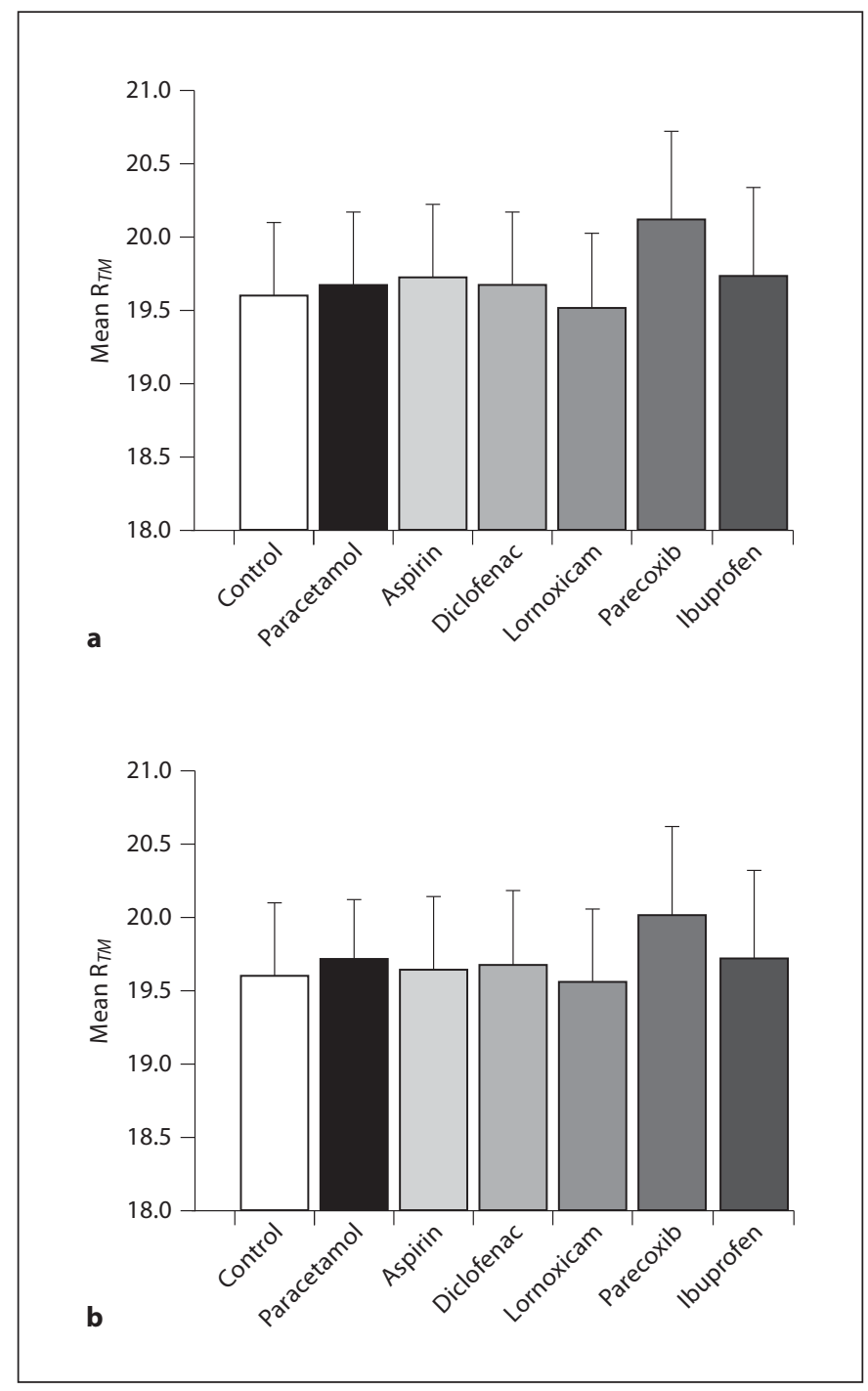

Fig. 3. Effect of ouabain on the effect induced by paracetamol, acetylsalicylic acid, diclofenac, lornoxicam, parecoxib and ibuprofen on the $\mathrm{R}_{T M}$ of the mesothelial (a) and interstitial (b) surfaces of the human parietal pleura, within the first minute after addition. Values are expressed as mean $\mathrm{R}_{T M} \pm \mathrm{SE}$ in $\Omega \cdot \mathrm{cm}^{2}$.

thelial ( $\mathrm{p}=0.934$, fig. $2 \mathrm{a})$ and interstitial surfaces $(\mathrm{p}=$ 0.993 , fig. $2 b$ ). Ouabain also inhibited the aforementioned effect on the mesothelial ( $p=0.762$, fig. 3a) and interstitial $(p=0.954$, fig. $3 b)$ surfaces.

Diclofenac also induced a rapid and significant increase of $\mathrm{R}_{T M}$ when added on both the mesothelial ( $\mathrm{p}=$ 0.012 , fig. 1a) and interstitial surfaces ( $p=0.008$, fig. $1 \mathrm{~b}$ ) of the pleural specimens. Again amiloride inhibited this
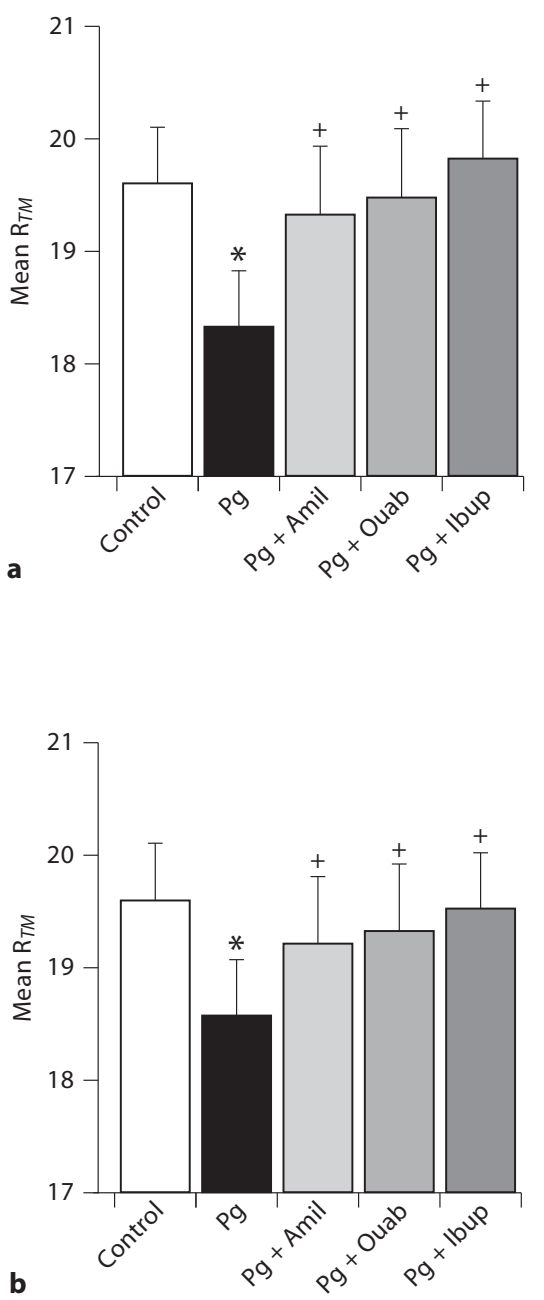

Fig. 4. Effect of prostaglandin (Pg), prostaglandin and amiloride (Amil), prostaglandin and ouabain (Ouab) and prostaglandin and ibuprofen (Ibup) on the $\mathrm{R}_{T M}$ of the mesothelial (a) and interstitial (b) surfaces of the human parietal pleura, within the first minute after addition. Values are expressed as mean $\mathrm{R}_{T M} \pm \mathrm{SE}$ in $\Omega \cdot \mathrm{cm}^{2} \cdot{ }^{*} \mathrm{p}<0.05$ for prostaglandin vs. control, ${ }^{+} \mathrm{p}<0.05$ for prostaglandin plus amiloride and prostaglandin plus ouabain vs. prostaglandin.

effect on both the mesothelial ( $p=0.863$, fig. $2 a$ ) and interstitial surfaces ( $p=0.883$, fig. $2 b$ ) and ouabain had a similar effect on the mesothelial $(\mathrm{p}=0.892$, fig. $3 \mathrm{a})$ and interstitial surfaces ( $p=0.658$, fig. $3 b)$.

A similar effect was induced by lornoxicam within the first minute after addition, i.e. $\mathrm{R}_{T M}$ significantly increased on both the mesothelial ( $p=0.028$, fig. 1a) and interstitial surfaces ( $p=0.033$, fig. $1 b)$. Amiloride inhib- 
ited this effect on both the mesothelial ( $p=0.928$, fig. $2 a$ ) and interstitial surfaces ( $p=0.228$, fig. $2 b)$. Oubain also inhibited lornoxicam's effect on both the mesothelial $(\mathrm{p}=0.438$, fig. $3 \mathrm{a})$ and interstitial $(\mathrm{p}=0.588$, fig. $3 \mathrm{~b})$ surfaces.

Parecoxib had a weak effect on the $\mathrm{R}_{T M}$ of the pleural specimens when added on the mesothelial $(p=0.078$, fig. 1a) and interstitial ( $p=0.248$, fig. $1 b)$ surfaces, which were not totally inhibited by amiloride $(\mathrm{p}=0.08$, fig. $2 \mathrm{a}$ for the mesothelial and $p=0.198$, fig. $2 b$ for the interstitial surface) and ouabain ( $\mathrm{p}=0.09$, fig. 3a for the mesothelial and $p=0.128$, fig. $3 b$ for the interstitial surface).

The addition of ibuprofen significantly increased $\mathrm{R}_{T M}$ on both the mesothelial ( $p=0.001$, fig. 1a) and interstitial $(p=0.004$, fig. $1 b)$ surfaces of the pleura within the first minute after addition. Amiloride inhibited this effect on the mesothelial ( $p=0.932$, fig. $2 a$ ) and interstitial surfaces ( $p=0.893$, fig. $2 b$ ). Ouabain also inhibited ibuprofen's effect on the mesothelial $(p=0.942$, fig. $3 a)$ and interstitial surfaces ( $p=0.923$, fig. $3 b)$.

\section{Comparison of the Effects Induced by Inflammatory}

Drugs on the Electrophysiology of the Human Parietal Pleura

The comparison of the effect induced by the aboveinvestigated drugs revealed no difference among them except the comparison of the parecoxib effect on the mesothelial surface which was significantly different from the effect induced by paracetamol $(\mathrm{p}=0.048)$ and ibuprofen ( $p=0.042)$, and on the interstitial surface when compared to the effect produced by paracetamol $(\mathrm{p}=0.028)$ and ibuprofen $(p<0.01)$. Ibuprofen induced a higher effect on the interstitial surface in comparison with the other NSAIDs (vs. paracetamol p $=0.032$, acetylsalicylic acid $\mathrm{p}=0.018$, lornoxicam $\mathrm{p}=0.018$ and parecoxib $\mathrm{p}<$ 0.01 ).

The comparison of the effect induced by all drugs on the mesothelial with the effect induced on the interstitial surface revealed no difference.

\section{Effect of Prostaglandins on the Electrophysiology of} the Human Parietal Pleura

Prostaglandin at high concentration induced a rapid decrease of the $\mathrm{R}_{T M}$ within the first minute after addition when added on the mesothelial surface ( $p=0.021$, fig. $4 a)$. On the interstitial surface the decrease had the tendency to be statistically different ( $p=0.059$, fig. $4 b$ ).

Amiloride and ouabain also inhibited the effect of prostaglandins on the electrophysiology of the human parietal pleura on both surfaces ( $p=0.886$, fig. 4 a for me- sothelial and $p=0.799$, fig. $4 \mathrm{~b}$ for interstitial surface for amiloride, and $\mathrm{p}=0.936$, fig. $4 \mathrm{a}$ for mesothelial and $\mathrm{p}=$ 0.249 , fig. $4 \mathrm{~b}$ for interstitial surface for ouabain).

Prostaglandin, when added with ibuprofen, had no effect on the electrophysiology of the human parietal pleura on both surfaces ( $p=0.971$, fig. $4 \mathrm{a}$ for mesothelial and $\mathrm{p}=0.987$, fig. $4 \mathrm{~b}$ for interstitial surface).

\section{Discussion}

The main finding of the present study is that NSAIDs, except parecoxib, induce a rapid effect on the electrophysiology of the human parietal pleura by increasing the $\mathrm{R}_{T M}$ and consequently decreasing the overall permeability. This effect is mediated via the inhibition of the $\mathrm{Na}^{+}$ channels and $\mathrm{Na}^{+} / \mathrm{K}^{+}$pumps normally operating in the pleura, since it is blocked by amiloride and ouabain. Prostaglandin synthesis seems to be an intermediate event between the interaction of NSAIDs with the pleura and the inhibition of ion transportation, as prostaglandin $\mathrm{E}_{2}$ induced an opposite effect to the NSAIDs effect by rapidly decreasing the $\mathrm{R}_{T M}$ and therefore increasing the pleural permeability, an effect again inhibited by the ion transporter blockers amiloride and ouabain.

NSAIDs have been implicated in altering the endothelial permeability and the cellular transportation via ion channels in various tissues [12] such as the kidneys, where urinary sodium excretion was decreased and sodium absorption was increased by ibuprofen [1]. Indomethacin decreased the permeability increase induced by lung adenocarcinoma cells [2]. Ibuprofen also inhibited the current when basolaterally applied in Xenopus kidney A6 cell lines [12] while it suppressed the upregulation of $\mathrm{Na}^{+}$ channels in the small dorsal root ganglion [13], an effect also observed with celecoxib [14]. The inhibition of various ion channels by NSAIDs, such as celecoxib, has been demonstrated in retinal neurons as well [15]. Ion cellular transporters, such as amiloride-sensitive $\mathrm{Na}^{+}$channels, ouabain-sensitive $\mathrm{Na}^{+} / \mathrm{K}^{+}$pumps, glibenclamide-sensitive $\mathrm{K}^{+}$channels and others were previously shown to be present in the pleura, producing a pleural fluid recycling potential operating under normal conditions [8-10]. This study suggests that these ion transporters operating in the pleura are inhibited by NSAIDs, decreasing its permeability and therefore hindering part of the pleural fluid recycling process.

It has been debated whether specific cyclooxygenase-2 (COX-2) inhibitors induce less and weaker side effects than the other nonselective NSAIDs [16]. These selective 
inhibitors were considered to offer a better inflammatory pleural response in pleurodesis [17], thereby overcoming the decreased quality of pleural adhesions during pleurodesis induced by the nonselective NSAIDs $[1,6$, 18]. Celecoxib, on the other hand, is considered to inhibit $\mathrm{Na}^{+}$channels in dorsal root ganglion neurons [14] or in rat retinal neurons [15]. COX-2 expression stimulated hyperosmolality in kidney cells [19]. Parecoxib had a weak effect on permeability alterations in the pleura, as shown by the present study, suggesting that the selective COX-2 inhibitors do not seem to influence the normal pleural fluid recycling, an event extremely important especially postoperatively, where the fluid redistribution between the pleural space and the systemic circulation is altered.

Prostaglandin synthesis is being selectively or nonselectively inhibited by the NSAIDs. This inhibition is believed to be associated with the involvement of NSAIDs in the permeability alterations in different tissues [1]. Prostaglandin $\mathrm{E}_{2}$ seems to play an important role in mediating the aforementioned effect $[1-3,12]$. High concentrations are needed for this effect to be induced by prostaglandin $\mathrm{E}_{2}$ [2]. In dorsal root ganglion cells, prostaglandins seem to augment sodium channel signaling [13] while endothelial permeability to albumin is decreased by prostaglandins [20]. Results from this study show that prostaglandins augment pleural permeability via cellular transportation, an effect opposite to the effect induced by NSAIDs. Therefore, prostaglandin synthesis inhibition follows the interaction of NSAIDs with the pleura, which eventually results in hindered cellular transportation via $\mathrm{Na}^{+}$channels and $\mathrm{Na}^{+} / \mathrm{K}^{+}$pumps. The fact that high concentrations of prostaglandins are needed for the abovementioned effect to be observed in the pleura explains the fact that cellular transportation is not altered by prostaglandins at normal concentrations produced in mesothelial pleural cells.

The use of different kinds of NSAIDs is frequently involved in clinical practice as, for instance, in postoperative pain control treatment [5]. Results from this study suggest that clinicians should consider the effects of each type of NSAID. In cases of an unexplained postoperative persistent effusion, a thorough review of the analgesics administered should be performed and changed to NSAIDs not affecting permeability, as indicated in this study. However, this study has limitations, such as the fact that the inhibition of COX-1 [21] or the effect of other prostaglandins was not investigated. Another limitation of the study is that it was performed on normal tissues and not on inflammatory tissues which express different types of cyclooxygenases (COX-2 more specifically), an event that could partially explain the fact that parecoxib did not alter pleural permeability.

In conclusion, NSAIDs induce a rapid decrease of the pleural permeability by inhibiting cellular transportation, an effect that is mediated by prostaglandin synthesis inhibition. Parecoxib was the only NSAID that induced a nonsubstantial effect. Thoracic surgeons should consider this information when managing postoperative pain.

\section{References}

$\checkmark 1$ Lauridsen TG, Vase H, Starklint J, Graffe CC, Bech JN, Nielsen S, Pedersen EB: Increased renal sodium absorption by inhibition of prostaglandin synthesis during fasting in healthy man. A possible role of the epithelial sodium channels. BMC Nephrol 2010;11:28.

-2 Payne DK, Fuseler JW, Owens MW: Modulation of endothelial cell permeability by lung carcinoma cells: a potential mechanism of malignant pleural effusion formation. Inflammation 1994;18:407-417.

$>3$ Ohishi S: Evaluation of time course and inter-relationship of inflammatory mediators in experimental inflammatory reaction. Yakugaku Zasshi 2000;120:455-462.

$>4$ Iwamura S, Kambegawa A, Miyasaka K: Relationship between the anti-inflammatory effects and intrapleural accumulations of anti-inflammatory drugs in rats carrageenin pleurisy. J Pharmacobiodyn 1984;7:517-526.
5 Lardinois D, Vogt P, Yang L, Hegyi I, Baslam M, Weder W: Non-steroidal anti-inflammatory drugs decrease the quality of pleurodesis after mechanical pleural abrasion. Eur J Cardiothorac Surg 2004;25:865-871.

-6 Teixeira LR, Vargas FS, Acencio MM, Paz PF, Antonangelo L, Vaz MA, Marchi E: Influence of antiinflammatory drugs (methylprednisolone and diclofenac sodium) on experimental pleurodesis induced by silver nitrate or talc. Chest 2005;128:4041-4045.

$>7$ Kouritas VK, Tsantsaridou A, Tepetes K, Tsilimingas N, Gourgoulianis KI, Molyvdas PA, Hatzoglou C: Effect of histamine on the electrophysiology of the human parietal pleura. Mol Cell Endocrinol 2011;332:271276.

$>8$ Hatzoglou CH, Gourgoulianis KI, Molyvdas PA: Effects of SNP, ouabain and amiloride on electrical potential profile of isolated sheep pleura. J Appl Physiol 2001;90:15651569.
9 Kouritas VK, Hatzoglou C, Foroulis CN, Hevas A, Gourgoulianis KI, Molyvdas PA: Low glucose level and low pH alter the electrochemical function of human parietal pleura. Eur Respir J 2007;30:354-357.

10 Kouritas VK, Hatzoglou C, Gourgoulianis KI, Molyvdas PA: Pleural electrophysiology variations according to location in pleural cavity. Interact Cardiovasc Thorac Surg 2009;9:391-394.

11 Deng X, Wang X, Andersson R: Influence of anti-inflammatory and antioxidant agents on endothelial permeability alterations induced by bradykinin. J Invest Surg 1996;9: 337-349.

12 Worrell RT, Bao HF, Denson DD, Eaton DC: Contrasting effects of cPLA2 on epithelial $\mathrm{Na}^{+}$transport. Am J Physiol Cell Physiol 2001;281:C147-C156. 
13 Gould HJ 3rd, England JD, Soignier RD, Nolan P, Minor LD, Liu ZP, Levinson SR, Paul D: Ibuprofen blocks changes in $\mathrm{Na} v 1.7$ and 1.8 sodium channels associated with complete Freund's adjuvant-induced inflammation in rat. J Pain 2004;5:270-280.

- 14 Park SY, Kim TH, Kim HI, Shin YK, Lee CS, Park M, Song JH: Celecoxib inhibits $\mathrm{Na}^{+}$currents in rat dorsal root ganglion neurons. Brain Res 2007;1148:53-61.

15 Frolov RV, Slaughter MM, Singh S: Effects of celecoxib on ionic currents and spontaneous firing in rat retinal neurons. Neuroscience 2008;154:1525-1532.
6 Bjarnason I, Takeuchi K: Intestinal permeability in the pathogenesis of NSAID-induced enteropathy. J Gastroenterol 2009;44: 23-29.

17 Teixeira LR, Vargas FS, Acencio MM, Antonangelo L, Novaes NP, Costa JD Jr, Marchi $\mathrm{E}$ : Influence of parecoxib (cox-2 inhibitor) in experimental pleurodesis. Respir Med 2009; 103:595-600.

18 Ors Kaya S, Bir F, Atalay H, Onem G, Aytekin FO, Saçar M: Effect of diclofenac on experimental pleurodesis induced by tetracycline in rabbits. J Investig Med 2005;53:267270.

19 Steinert D, Küper C, Bartels H, Beck FX, Neuhofer W: $\mathrm{PGE}_{2}$ potentiates tonicity-induced COX-2 expression in renal medullary cells in a positive feedback loop involving EP2-cAMP-PKA signaling. Am J Physiol Cell Physiol 2009;296:C75-C87.
20 Farmer PJ, Bernier SG, Lepage A, Guillemette G, Regoli D, Sirois P: Permeability of endothelial monolayers to albumin is increased by bradykinin and inhibited by prostaglandins. Am J Physiol Lung Cell Mol Physiol 2001;280:L732-L738.

21 Hotz-Behofsits C, Simpson RJ, Walley M, Bjarnason IT: Role of COX-2 in nonsteroidal anti-inflammatory drug enteropathy in rodents. Scand J Gastroenterol 2010;45:822827. 